\title{
Dielectric Bamier Discharge Plasma Activates Persulfate to Degrade Norfloxacin: Mechanism and Degradation Pathways
}

\author{
Cao Fang ${ }^{a, b}$ \& Qing Huang,a,

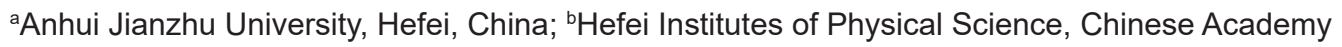 \\ of Sciences, Hefei, China \\ *Address all correspondence to: Qing Huang, Hefei Institutes of Physical Science, Chinese Academy of Sciences, \\ Hefei 230031, China; Tel.: +86-551-65595261; Fax: +86-551-65595261, E-mail: huangq@ipp.ac.cn
}

\begin{abstract}
In these studies, sodium persulfate was activated by atmospheric pressure nonthermal dielectric barrier discharge (DBD) plasma to degrade norfloxacin in aqueous solution. Our results showed that the degradation of norfloxacin could be remarkably enhanced with the addition of sodium persulfate to the norfloxacin solution treated by DBD in an oxygen atmosphere. The relationship between the degradation efficiency and the concentration of sodium persulfate is examined, and the possible degradation reaction pathways and mechanisms are discussed.
\end{abstract}

KEY WORDS: non-thermal plasma, sodium persulfate, degradation, antibiotics

\section{INTRODUCTION}

Norfloxacin is a fluoroquinolone that is used in human and animal disease control, animal husbandry, aquaculture, and agriculture. ${ }^{1}$ It is also one of most frequently detected fluoroquinolones in drinking water and wastewater. ${ }^{2}$ Conventional methods applied in wastewater treatment plants show low efficiency in the removal of antibiotic drugs, and antibiotic residues in natural water are potentially harmful to the environment and human health. ${ }^{3}$ Therefore, it is necessary to explore more efficient, nontoxic, convenient ways to remove antibiotic drugs from wastewater.

Conventional approaches to remove norfloxacin from wastewater include those based on adsorption, ${ }^{4-6}$ photocatalysis, ${ }^{7-9}$ electrochemistry, ${ }^{10,11}$ biodegradation, ${ }^{12-14}$ and the Fenton reaction. ${ }^{15-17}$ Because the benzene ring of norfloxacin is difficult to biodegrade in conventional wastewater treatment processes, alternative methods such as advanced oxidation technology are proposed to degrade and remove norfloxacin. ${ }^{18,19}$

In this context, non-thermal plasma as an effective advanced oxidation technology has attracted increasing attention for its broad research and application prospects. ${ }^{20,21}$ For example, researchers have used arc discharge plasma to degrade acetaminophen, ${ }^{22}$ and they have used non-thermal plasma to degrade crystal violet. ${ }^{23}$ Meanwhile, DBD plasma has a high degree of efficiency and has received considerable attention in water treatment. ${ }^{24}$ According to the reports, the researchers used DBD plasma to degrade toxic 2,4-dichlorophenol ${ }^{25}$ and developed a novel coaxial DBD reactor to degrade aniline in aqueous solution. ${ }^{26}$ Recently, our group also applied DBD to degrade nor- 
floxacin and revealed the mechanism for the major degradation pathways through hydroxyl radicals. ${ }^{27}$

Persulfate is often applied in advanced oxidation technology that generally needs to be activated by some means, such as ultraviolet (UV) light, iron, or heat. For example, pyrite and heat can be used to activate persulfate to degrade ethyl thiocarbamate ${ }^{28}$ and benzoic acid. ${ }^{29}$ Other researchers used UV light to activate persulfate to degrade naphthenic acid compounds in aqueous solutions. ${ }^{30}$ Plasma can produce many active substances, such as $\mathrm{UV}, \bullet \mathrm{OH}, \bullet \mathrm{O}$ and hydrated electron. ${ }^{31,32}$ Therefore, some researchers also employed plasma to activate persulfate to degrade organic substances, such as acid orange $7(\mathrm{AO} 7)^{33}$ and crystal violet. ${ }^{34}$

Therefore, in this work, we attempted to employ non-thermal DBD plasma to activate persulfate to improve norfloxacin treatment efficiency, compare the effects of persulfate activation under different gas discharge conditions, and investigate the mechanisms for the involved degradation reactions.

\section{MATERIALS AND METHODS}

\section{A. Experimental Materials}

Norfloxacin (purity $>98 \%$ ) was purchased from Shanghai Shenggong Bioengineering Co., Ltd. Sodium persulfate (analytical grade), methanol (analytical grade), ethanol (analytical grade), acetonitrile (chromatographic grade), phosphoric acid (analytical grade), and formic acid (chromatographic grade) were purchased from Sinopharm Chemical Reagent Co. Ltd., China. Gases such as argon (Ar), nitrogen $\left(\mathrm{N}_{2}\right)$, and oxygen $\left(\mathrm{O}_{2}\right)$ are supplied by Hefei Lanye Medical Oxygen Company (Hefei, China), and the purity of all gases used for plasma discharge in the experiment was greater than $99.99 \%$. The V-60 ultra-quiet air pump for generating air was supplied by Guangdong Haili Group Co., Ltd. All other chemicals in the experiment were of analytical grade and could be used without further purification. All the solutions used in the experiment were prepared from ultrapure water.

\section{B. DBD Experimental Setup}

Figure 1 illustrates a schematic diagram of our plasma experimental setup, which was also described in our previous work. In short, the upper and lower plates of the DBD reactor were made of stainless steel, and the reactor made of quartz dish was placed in the middle of the two plates and contained the solution of norfloxacin. The gap between the quartz plate and the water surface was filled with different discharge gases (argon, nitrogen, oxygen, and air) at a flow rate of $0.5 \mathrm{~L} / \mathrm{min}$. The distance between the quartz plate and the surface of the solution was approximately $5 \mathrm{~mm}$. During the discharge, the lower plate was grounded and the upper plate was connected to a high-frequency AC power supply (CTP-2000K/P, Nanjing Suman Electronics Co., Ltd., China), with the input voltage about $10 \mathrm{kV}$, and the power supply frequency in the range of 5 to $25 \mathrm{kHz}$. 


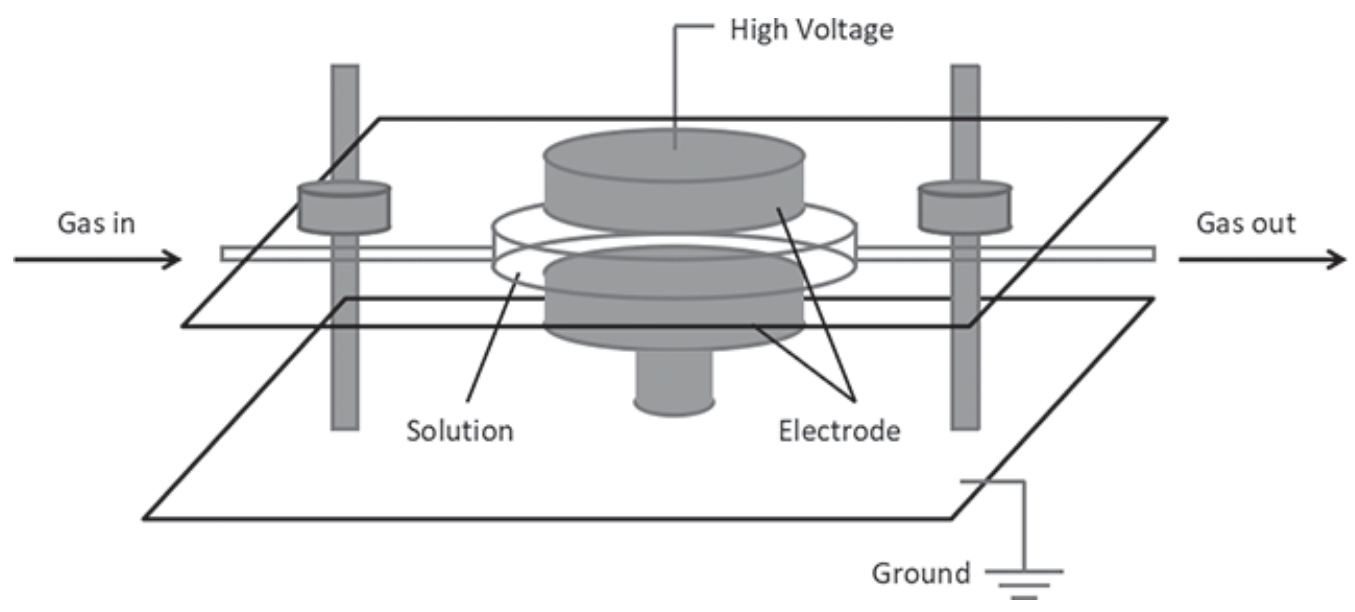

FIG. 1: Schematic diagram of the DBD reactor for norfloxacin treatment

\section{Expenimental Methods}

\section{Preparation and Treatment of Solution Samples}

Norfloxacin solutions and sodium persulfate (PDS) solutions were prepared using ultrapure water (resistivity of about $18.25 \mathrm{M} \Omega / \mathrm{cm}$ ). The concentration of norfloxacin solution was $200 \mathrm{mg} / \mathrm{L}$, and the concentration gradient of sodium persulfate was $0.05,0.1$, $0.2,0.5,0.8,1.2 \mathrm{~mol} / \mathrm{L}$, respectively. The sample of norfloxacin solution was treated with DBD under different conditions by adding different concentrations of sodium persulfate solutions $(0.025,0.05,0.1,0.25,0.4,0.6 \mathrm{~mol} / \mathrm{L})$ into the norfloxacin solution $(200 \mathrm{mg} / \mathrm{L})$ at $1: 1$ volume ratio. Four $\mathrm{mL}$ of the mixture was loaded into a quartz dish reactor and covered with a quartz plate. The concentration of norfloxacin was determined based on the absorption peak at $278 \mathrm{~nm}$.

\section{HPLC Analysis}

After the DBD treatment, the samples were analyzed by high performance liquid chromatography (HPLC, Shimadzu, Japan), which was equipped with a UV detector and an InertSustain C18 column $(5 \mu \mathrm{m}, 4.6 \times 250 \mathrm{~mm})$. The mobile phase was a 20:80 (v/v) solution of acetonitrile and phosphoric acid $(25 \mathrm{mmol} / \mathrm{L})$, with the flow rate at $1.0 \mathrm{~mL} / \mathrm{min}$.

\section{HPLC-MS Analysis}

The reaction intermediates and products from the norfloxacin degradation process were analyzed by HPLC-MS (LTQ Orbitrap XL, Thermo Fisher Scientific) equipped with a C18 column $(250 \mathrm{~mm} \times 4.6 \mathrm{~mm} ; 5 \mu \mathrm{m})$. The electrospray ion source uses a positive 
ionization mode. The mobile phase was 80:20 (v/v) 0.1\% aqueous formic acid and acetonitrile, and the flow rate was set to $300 \mu \mathrm{L} / \mathrm{min}$.

\section{RESULTS AND DICUSSION}

\section{A. Effect of Different Treatment Methods on the Degradation Rate of Norfoxacin}

Figure 2 shows the degradation rate of norfloxacin with treatments using different methods. The degradation rate of norfloxacin was about $40 \%$ by air DBD for 6 min. The concentration of norfloxacin hardly changed using pure sodium persulfate for the treatment. However, when air DBD was applied with $0.025 \mathrm{~mol} / \mathrm{L}$ sodium persulfate in the solution, the degradation rate of norfloxacin was increased to about $55 \%$, confirming the effect of plasma on the activation persulfate.

\section{B. Effect of Different Disc harge Gases on the Degradation Rate of Norfloxacin}

Figure 3 shows the effect of activating persulfate with different gas discharges. Without adding sodium persulfate, argon DBD showed the highest degradation rate, and in contrast, nitrogen DBD showed relatively inefficient degradation rate compared with other gas discharges. Keeping the same discharge conditions while adding $0.025 \mathrm{~mol} / \mathrm{L}$ of sodium persulfate into the norfloxacin solution, the degradation rate was significantly

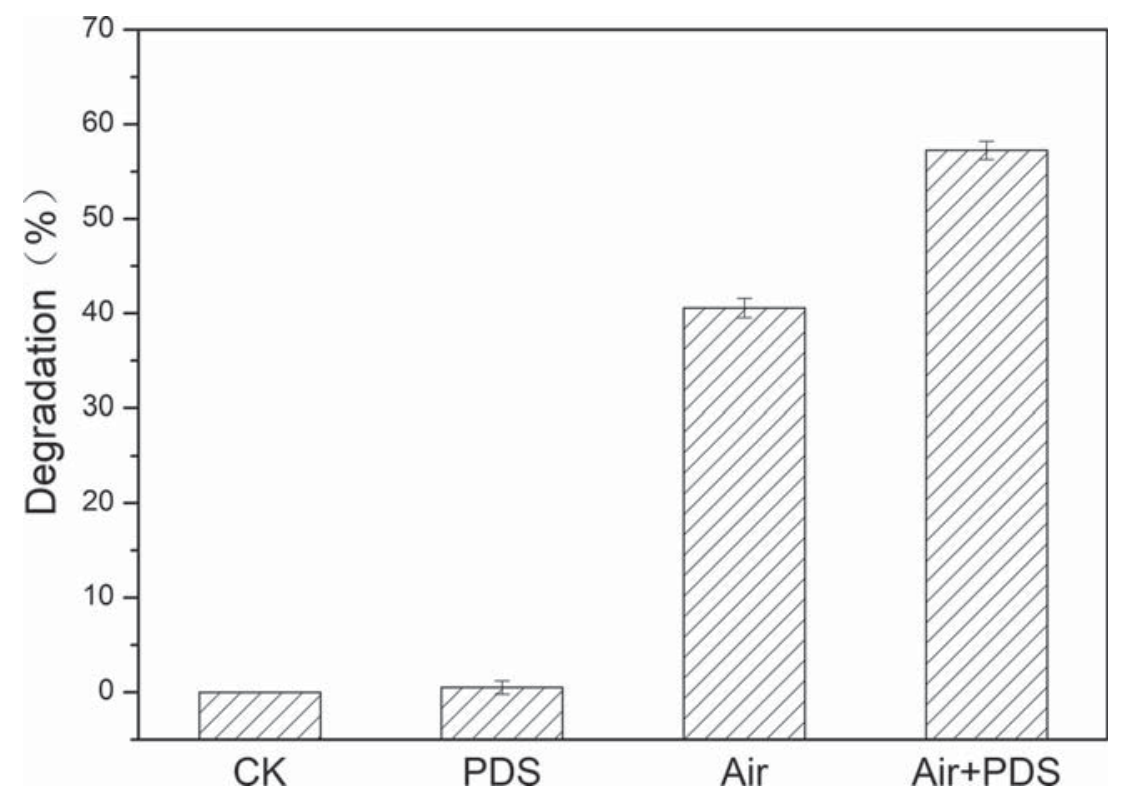

FIG. 2: The degradation efficiency of norfloxacin by treatment using different methods 


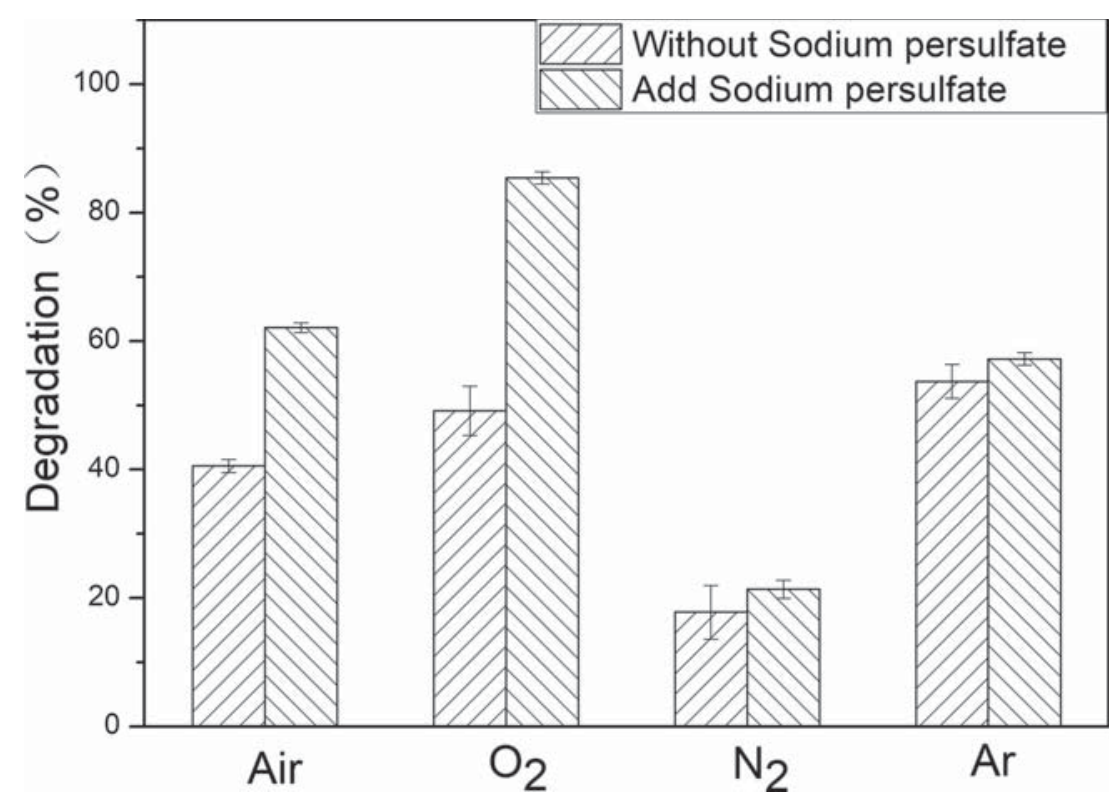

FIG. 3: The degradation rate of norfloxacin by treatment using different gas discharge

increased. The molar ratio of norfloxacin to sodium persulfate was about 1:40. Although sodium persulfate alone did not contribute to the degradation (as shown previously in Fig. 2), the combined effect of oxygen DBD and sodium persulfate yielded the best treatment results. The degradation rate was about $86 \%$ after 4 min of treatment. So in the following experiments, we focused on the oxygen DBD treatment and discussed its degradation efficiency and mechanism.

\section{Effect of Persulfate Concentration on the Degradation Rate of Norfloxacin}

Figure 4 shows the relationship between the degradation rate of norfloxacin and the concentration of sodium persulfate. The initial concentration of sodium persulfate was 0.025 $\mathrm{mol} / \mathrm{L}$. As the persulfate concentration was increased, the degradation rate increased accordingly. When the concentration of sodium persulfate was less than $0.2 \mathrm{~mol} / \mathrm{L}$, the degradation rate of norfloxacin changed almost linearly with the concentration of sodium persulfate. But when the concentration of sodium persulfate was higher than 0.2 $\mathrm{mol} / \mathrm{L}$, the degradation rate of norfloxacin did not increase much with the increase of sodium persulfate concentration. A possible reason for this phenomenon is that, on the one hand, increasing the concentration of sodium persulfate can promote the production of various active free radicals. On the other hand, the probability of free radical recombination rate in the reaction also increases under the condition of high concentration of free radicals, thus causing the quenching reaction between the free radicals. ${ }^{35}$ Therefore, excessively increasing the concentration of sodium persulfate could not promote the

Volume 8, Issue 4, 2018 


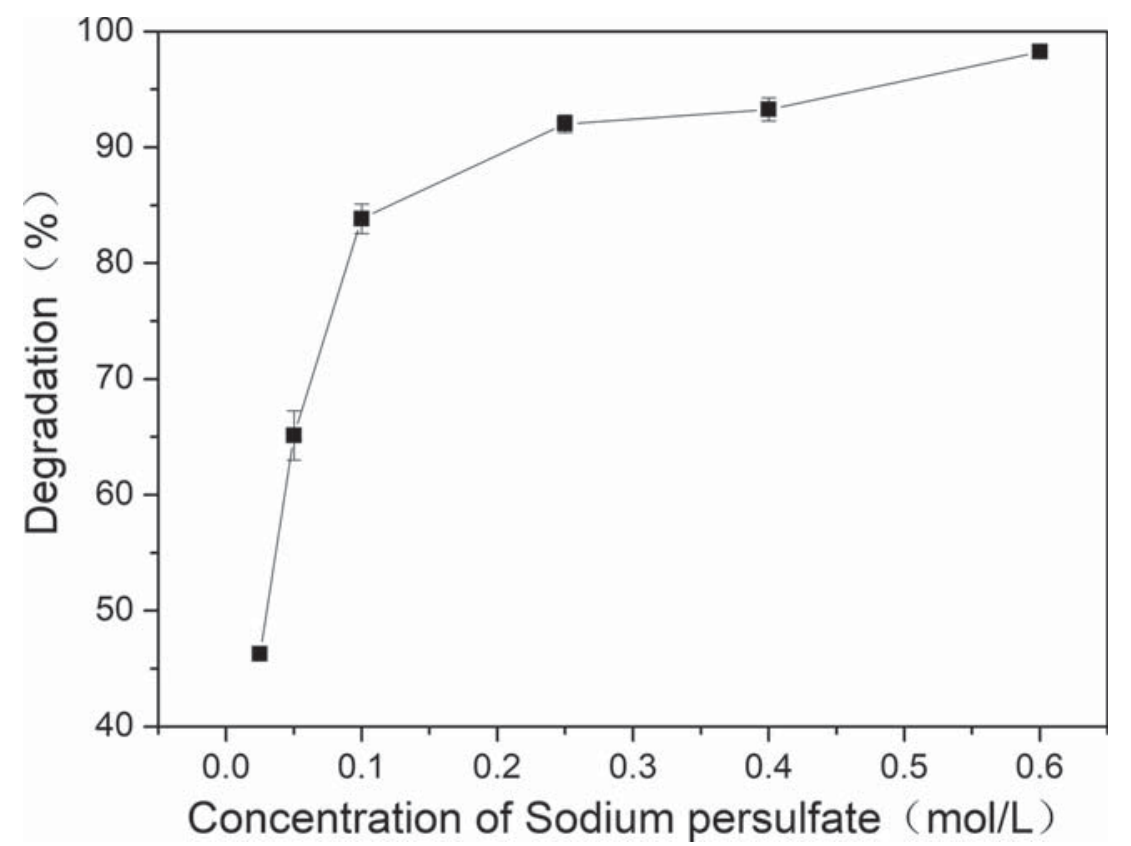

FIG. 4: Relationship between the degradation rate of norfloxacin and the concentration of sodium persulfate

degradation of norfloxacin at high concentrations of sodium persulfate. Therefore, it is necessary to choose optimal sodium persulfate concentration for the desired efficiency of treatment. In this case, we recommend adding sodium persulfate with concentration less than $0.2 \mathrm{~mol} / \mathrm{L}$, which may also prevent secondary contamination in the treatment. ${ }^{33}$

\section{Mechanism of Degradation and Possible Degradation Process}

In the DBD plasma, the accompanying physical and chemical effects are due to multiple factors, such as high energy electrons, electric fields, local high temperature, hydrated electrons, ultraviolet radiation, hydroxyl radicals and other oxygen reactive species. ${ }^{31,32}$ These factors may all work together to activate sodium persulfate to produce the stronger oxidant through the following reactions: $:^{35,36}$

$$
\begin{gathered}
\mathrm{S}_{2} \mathrm{O}_{8}^{2-} \stackrel{\text { DBDP }}{\longrightarrow} \mathrm{SO}_{4}^{-} \cdot+\mathrm{SO}_{4}^{-} \\
\mathrm{SO}_{4}^{-} \cdot+\mathrm{OH}^{-} \rightarrow \cdot \mathrm{OH}+\mathrm{SO}_{4}^{2-} \\
\mathrm{SO}_{4}^{-\cdot}+\mathrm{H}_{2} \mathrm{O}^{-} \rightarrow \cdot \mathrm{OH}+\mathrm{HSO}_{4}^{-} \\
2 \cdot \mathrm{OH} \rightarrow \mathrm{H}_{2} \mathrm{O}_{2}
\end{gathered}
$$


In our experiments, the treatment time was relatively short (the longest treatment time was $6 \mathrm{~min}$ ). Yet it normally takes longer for UV light to activate the persulfate, ${ }^{37}$ so the influence of the UV light could be neglected in our case. Meanwhile, the sulfate radicals can also react with water to form hydroxyl radicals, and hydroxyl radicals would become the main active species in the alkaline environment. Sulfate radicals are the main active substances in acidic environments, so both hydroxyl and sulfate radicals participate in the reactions in a neutral environment. ${ }^{38}$ Because our experiment was carried out in an acidic environment, the main active species contributing to the reaction was sulfate radicals. For the degradation by oxygen DBD, which showed the best treatment, this could be due to the fact that some active substances, such as $\mathrm{O}_{3}$ and $\mathrm{O} \cdot$, were produced in the reaction of oxygen discharge. The presence of these substances might further promote the activation of sodium persulfate. ${ }^{39,40} \mathrm{SO}^{-} \cdot$ can react more selectively and efficiently by electron transfer with groups containing unsaturated bonds or aromatic $\pi$ bonds..$^{41}$ In addition, $\mathrm{SO}^{-} \cdot$ has a longer lifetime in the water than $\bullet \mathrm{OH}$, which can continuously oxidize more organic substances in water. ${ }^{42}$ Considering these factors, we expect that the addition of persulfate during oxygen discharge could thus significantly improve the degradation efficiency of norfloxacin.

According to previous reports, the degradation products of norfloxacin are mainly formed from the breakage of the piperazine ring and the six-membered ring. ${ }^{27,43}$ To investigate the degradation pathways, mass spectrometry was used to analyze the process of possible degradation reactions. Figure 5 shows the mass spectra of degradation rate of norfloxacin by DBD alone and by DBD plus sodium persulfate, respectively. We

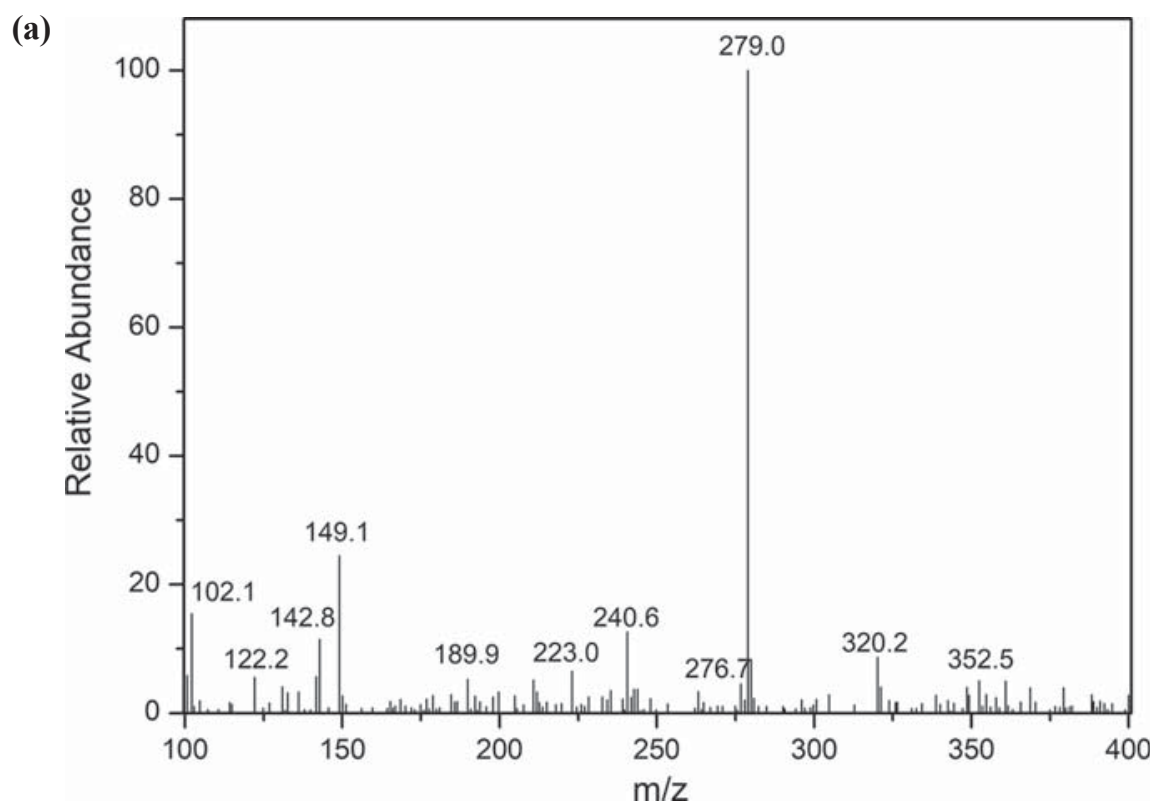

FIG. 5.

Volume 8, Issue 4, 2018 
(b)

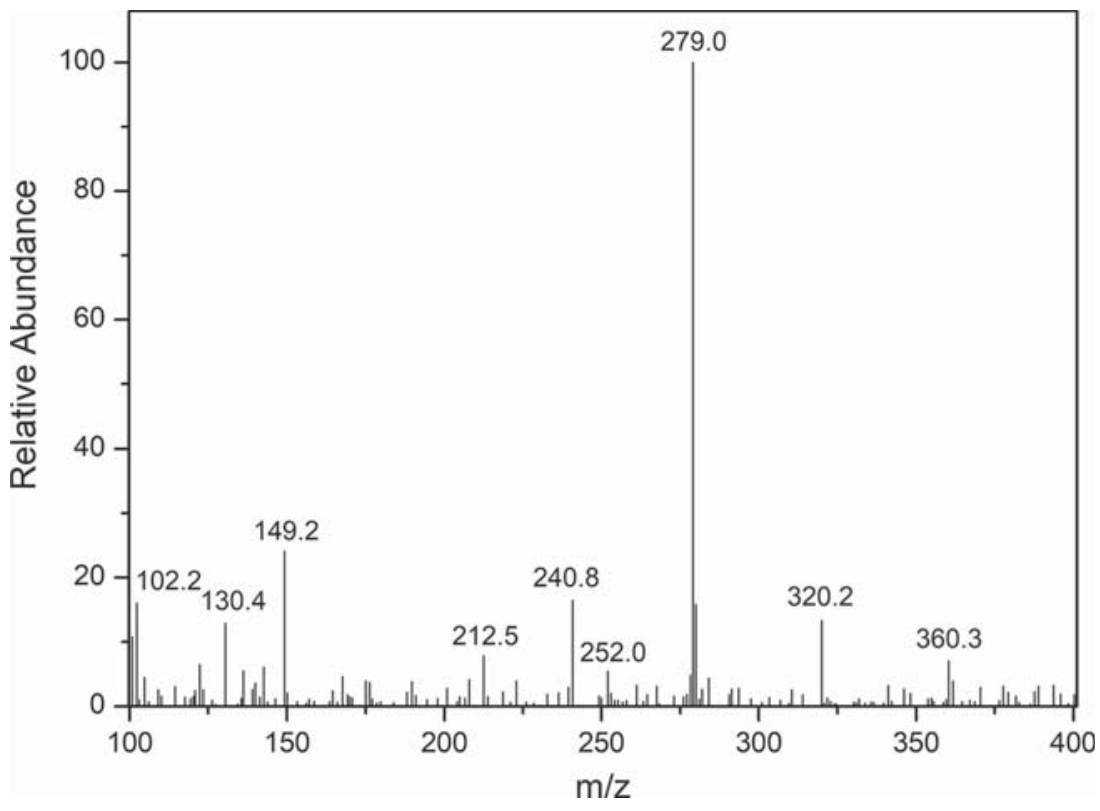

(c)

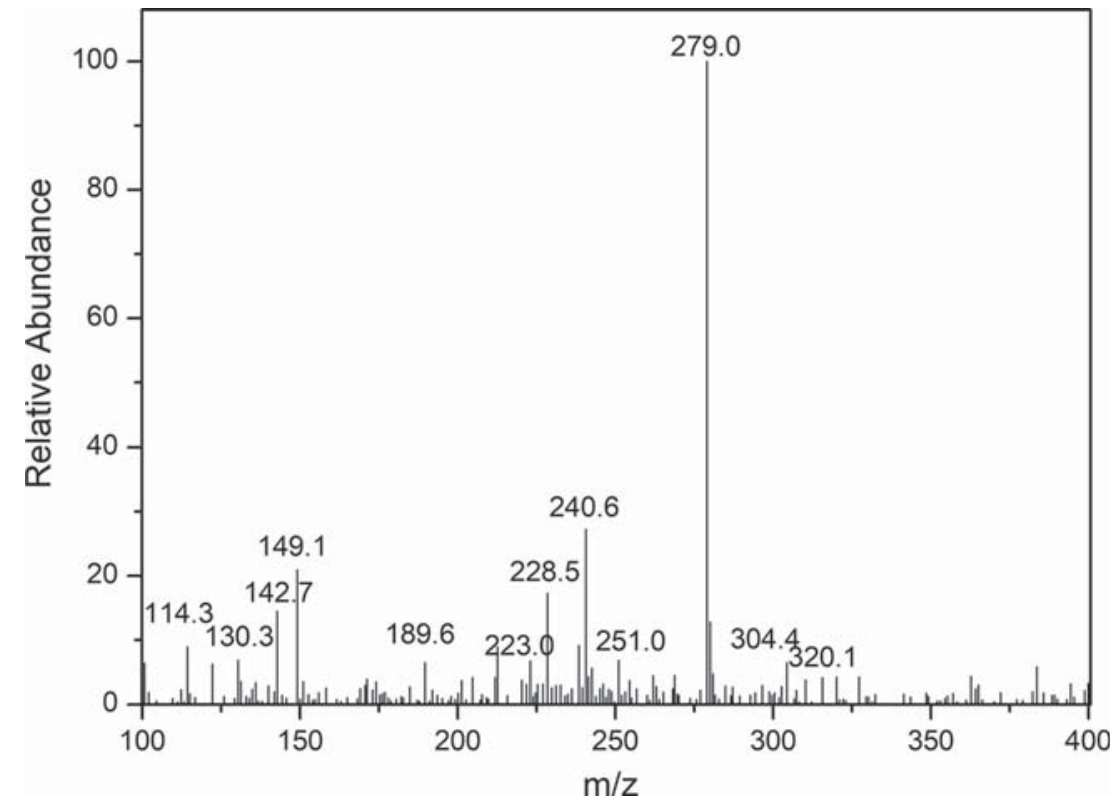

FIG. 5: The mass spectra for degradation of norfloxacin by $\operatorname{DBD}(\mathrm{a}, \mathrm{b})$ and $\mathrm{DBD}+$ persulfate $(\mathrm{c})$

speculated the possible products and pathways for the norfloxacin degradation based on the mass spectra and information acquired from previous studies.

Figure $6 \mathrm{a}$ and $\mathrm{b}$ depict the major possible pathways supported by the mass spectra obtained from our experiments using DBD alone and DBD plus persulfate, respectively. 
Notably, both treatments (DBD alone and DBD plus persulfate) in our experiments showed the strongest mass peak at $\mathrm{m} / \mathrm{z}=279$, which can be assigned to the product denoted as D2 and P3 in Fig. 6a and b, respectively. ${ }^{44}$ Some other peaks can also be detected; but because the signals are not very strong, we may neglect some pathways in the analysis. In the following discussion, we only emphasize the most evident degradation pathways, but not excluding other possible pathways as reported in the literature.

Figure 6a shows the possible degradation pathways for the DBD treatment alone. The degradation of norfloxacin is possibly attributed to the generation of ozone and hydroxyl radicals by plasma. From the product analysis, we can verify three paths of reactions. Specifically, Path I: the $\mathrm{C}-\mathrm{COOH}$ bond of norfloxacin $(\mathrm{m} / \mathrm{z}=320)$ is broken to form D1 $(\mathrm{m} / \mathrm{z}=276){ }^{45}$ Path II: the piperazine ring of norfloxacin is broken to form D2 $(\mathrm{m} / \mathrm{z}=279)$. Path III: the six-membered ring of norfloxacin is broken, forming D3 $(\mathrm{m} / \mathrm{z}=352)$; the five-membered ring continues to form the product $\mathrm{D} 4(\mathrm{~m} / \mathrm{z}=278)$; and finally the piperazine ring is broken to form D5 $(\mathrm{m} / \mathrm{z}=252){ }^{44,46}$

Figure $6 \mathrm{~b}$ shows the possible degradation pathways under the conditions of combined treatment with DBD and persulfate. The degradation of norfloxacin is attributed to the generation of ozone, hydroxyl radicals, and sulfate radicals. From the product

(a)
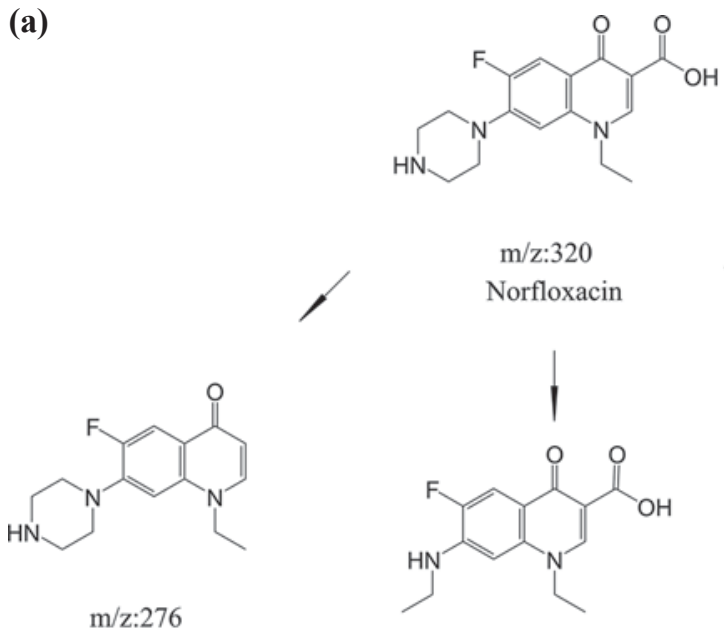

$\mathrm{m} / \mathrm{z}: 320$

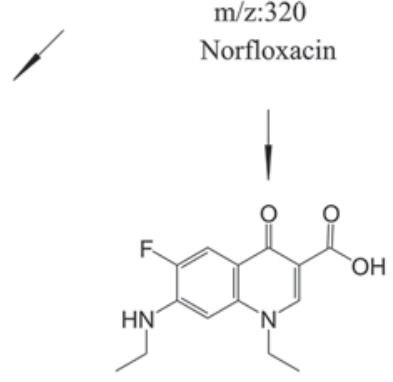

D1
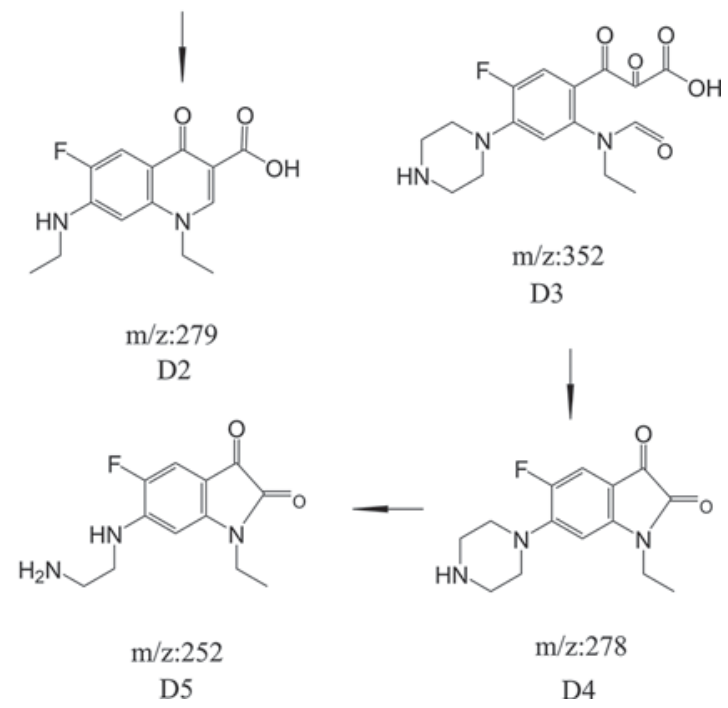

FIG. 6.

Volume 8, Issue 4, 2018 
(b)

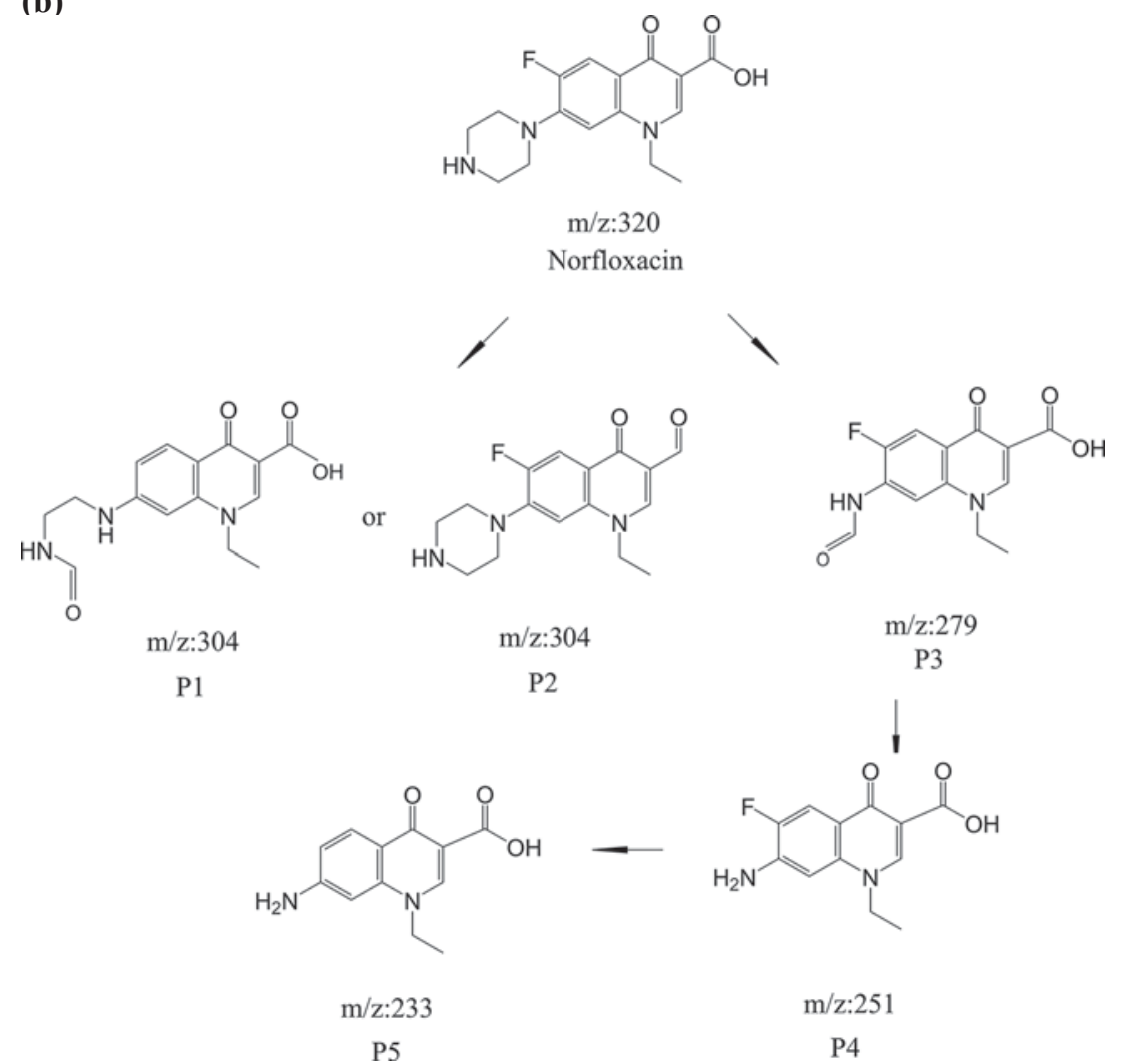

FIG. 6: (a) Possible degradation pathways of norfloxacin by oxygen-DBD alone; (b) Possible degradation pathways of norfloxacin by DBD with sodium persulfate present

analysis, we can verify at least two major paths of reactions. Specifically, Path I: the $\mathrm{C}-\mathrm{F}$ bond and piperazine ring of norfloxacin are broken to form P1 (m/z=304). ${ }^{27}$ This is in agreement with our previous work, in which hydroxyl radicals play the critical role, breaking the $\mathrm{C}-\mathrm{OH}$ bond of norfloxacin to form P2 $(\mathrm{m} / \mathrm{z}=304) .{ }^{47}$ Path II: the piperazine ring of norfloxacin is broken; the $\mathrm{C}=\mathrm{O}$ bond is formed; and the product is $\mathrm{P} 3(\mathrm{~m} / \mathrm{z}=$ 279). Next, the $\mathrm{C}-\mathrm{N}$ bond is broken to form $\mathrm{P} 4(\mathrm{~m} / \mathrm{z}=251)$, and finally the $\mathrm{C}-\mathrm{F}$ bond is broken to form P5 $(\mathrm{m} / \mathrm{z}=233){ }^{48,49}$ This agrees with previous work, in which sulfate radicals play the critical role in norfloxacin degradation.

To be noted, the oxidation mechanisms of $\mathrm{SO}_{4}^{-} \cdot$ and $\bullet \mathrm{OH}$ are different in some ways. Specifically, the $\mathrm{SO}_{4}^{-}$oxidation reaction is usually accompanied by only the electron transfer reaction, whereas the $\cdot \mathrm{OH}$ oxidation reaction goes through two processes of hydrogen atom extraction and electron transfer reaction. ${ }^{38}$ So in this work, we observed degradation pathways that are different from our previous work using DBD without persulfate. In this case, the degradation pathways of norfloxacin were mainly attributed to the fragmentation of piperazine groups by hydroxyl radicals. ${ }^{27} \mathrm{We}$ confirmed 
that the fracture of the piperazine ring and the six-membered ring in norfloxacin are the most important pathways in the process of norfloxacin degradation.

\section{CONCLUSION}

In summary, our research shows that DBD plasma can effectively activate persulfate and synergistically degrade norfloxacin. Activation of sodium persulfate by oxygen discharge shows the best degradation effect in the treatments. The possible degradation pathways and mechanisms of norfloxacin were proposed with the evidence that sulfate radicals play the critical role. As such, we have demonstrated that combining plasma and persulfate to treat norfloxacin is effective, and this work may also provide a guidance for pharmaceutical wastewater treatment.

\section{ACKNOWHDGENIS}

C.F. thanks Mr. Qifu Zhang for the assistance in the HPLC measurement, and Dr. Hong Zhang for help with the HPLC-MS measurement. This work was supported partly by the National Nature Science Foundation of China (Grant No. 11635013).

\section{REFERENCES}

1. Zhao J, Wu Y, Wu X, Wang C, Huang H, Lu J, Wu X, Cui J, Li C, Yan Y, Dong H. Insights into highefficiency molecularly imprinted nanocomposite membranes by channel modification for selective enrichment and separation of norfloxacin. J Taiwan Inst Chem Eng. 2018;89:198-07.

2. Bai J, Li Y, Jin P, Wang J, Liu L. Facile preparation 3D ZnS nanospheres-reduced graphene oxide composites for enhanced photodegradation of norfloxacin. J Alloys Compd. 2017;729:809-15.

3. Lindberg RH, Olofsson U, Rendahl P, Johansson MI, Tysklind M, Andersson BAV. Behavior of fluoroquinolones and trimethoprim during mechanical, chemical, and active sludge treatment of sewage water and digestion of sludge. Environ Sci Technol. 2006;40:1042-8.

4. Wang B, Jiang Y, Li F, Yang D. Preparation of biochar by simultaneous carbonization, magnetization and activation for norfloxacin removal in water. Bioresour Technol. 2017;233:159-65.

5. Wan Y, Liu X, Liu P, Zhao L, Zou W. Optimization adsorption of norfloxacin onto polydopamine microspheres from aqueous solution: kinetic, equilibrium and adsorption mechanism studies. Sci Total Environ. 2018;639:428-37.

6. Yan B, Niu CH. Adsorption behavior of norfloxacin and site energy distribution based on the Dubinin-Astakhov isotherm. Sci Total Environ. 2018;631-632:1525-33.

7. Tang J, Wang R, Liu M, Zhang Z, Song Y, Xue S, Zhao Z, Dionysiou DD. Construction of novel Zscheme $\mathrm{Ag} / \mathrm{FeTiO}_{3} / \mathrm{Ag} / \mathrm{BiFeO}_{3}$ photocatalyst with enhanced visible-light-driven photocatalytic performance for degradation of norfloxacin. Chem Eng J. 2018;351:1056-66.

8. Wang J, Tang L, Zeng G, Zhou Y, Deng Y, Fan C, Gong J, Liu Y. Effect of bismuth tungstate with different hierarchical architectures on photocatalytic degradation of norfloxacin under visible light. Trans Nonferrous Metals Soc China. 2017;27:1794-803.

9. Wen X, Niu C, Huang D, Zhang L, Liang C, Zeng G. Study of the photocatalytic degradation pathway of norfloxacin and mineralization activity using a novel ternary $\mathrm{Ag} / \mathrm{AgCl}-\mathrm{CeO}_{2}$ photocatalyst. J Catalysis. 2017;355:73-86.

Volume 8, Issue 4, 2018 
10. Mora-Gomez J, Ortega E, Mestre S, Pérez-Herranz V, García-Gabaldón M. Electrochemical degradation of norfloxacin using BDD and new Sb-doped $\mathrm{SnO}_{2}$ ceramic anodes in an electrochemical reactor in the presence and absence of a cation-exchange membrane. Sep Purif Technol. 2019;208:68-75.

11. Da Silva SW, Navarro EMO, Rodrigues MAS, Bernardes AM, Pérez-Herranz V. The role of the anode material and water matrix in the electrochemical oxidation of norfloxacin. Chemosphere. 2018; 210:615-23.

12. Zorita S, Mårtensson L, Mathiasson L. Occurrence and removal of pharmaceuticals in a municipal sewage treatment system in the south of Sweden. Sci Total Environ. 2009;407:2760-70.

13. Tegze A, Sági G, Kovács K, Homlok R, Tóth T, Mohácsi-Farkas C, Wojnárovits L, Takács E. Degradation of fluoroquinolone antibiotics during ionizing radiation treatment and assessment of antibacterial activity, toxicity and biodegradability of the products. Radiat Phys Chem. 2018;147:101-5.

14. Amorim CL, Maia AS, Mesquita RB, Rangel AO, van Loosdrecht MC, Tiritan ME, Castro PM. Performance of aerobic granular sludge in a sequencing batch bioreactor exposed to ofloxacin, norfloxacin and ciprofloxacin. Water Res. 2014;50:101-13.

15. Santos LVDS, Meireles AM, Lange LC. Degradation of antibiotics norfloxacin by Fenton, UV and $\mathrm{UV} / \mathrm{H}_{2} \mathrm{O}_{2}$. J Environ Manage. 2015;154:8-12.

16. Liu X, Zhou Y, Zhang J, Luo L, Yang Y, Huang H, Peng H, Tang L, Mu Y. Insight into electro-Fenton and photo-Fenton for the degradation of antibiotics: mechanism study and research gaps. Chem Eng J. 2018;347:379-97.

17. Zhou T, Zou X, Wu X, Mao J, Wang J. Synergistic degradation of antibiotic norfloxacin in a novel heterogeneous sonochemical Fe $\mathrm{F}^{0}$ tetraphosphate Fenton-like system. Ultrason Sonochem. 2017;37:320-27.

18. Van Doorslaer X, Dewulf J, Van Langenhove H, Demeestere K. Fluoroquinolone antibiotics: an emerging class of environmental micropollutants. Sci Total Environ. 2014;500-501:250-69.

19. Klavarioti M, Mantzavinos D, Kassinos D. Removal of residual pharmaceuticals from aqueous systems by advanced oxidation processes. Environ Int. 2009;35:402-17.

20. Wen Y, Shen C, Ni Y, Tong S, Yu F. Glow discharge plasma in water: a green approach to enhancing ability of chitosan for dye removal. J Hazard Mater. 2012;201-202:162-9.

21. Wu J, Li P, Tao D, Zhao H, Sun R, Ma F, Zhang B. Effect of solution plasma process with hydrogen peroxide on the degradation and antioxidant activity of polysaccharide from Auricularia auricula. Int J Biol Macromol. 2018;117:1299-304.

22. Slamani S, Abdelmalek F, Ghezzar MR, Addou A. Initiation of Fenton process by plasma gliding arc discharge for the degradation of paracetamol in water. J Photochem Photobiol A: Chem. 2018;359:1-10.

23. Chen J, Du Y, Shen Z, Lu S, Su K, Yuan S, Hu Z, Zhang A, Feng J. Non-thermal plasma and BiPO induced degradation of aqueous crystal violet. Sep Purif Technol. 2017;179:135-44.

24. Wang J, Sun Y, Feng J, Xin L, Ma J. Degradation of triclocarban in water by dielectric barrier discharge plasma combined with $\mathrm{TiO}_{2}$ /activated carbon fibers: effect of operating parameters and byproducts identification. Chem Eng J. 2016;300:36-46.

25. Zhang H, Zhang Q, Miao C, Huang Q. Degradation of 2,4-dichlorophenol in aqueous solution by dielectric barrier discharge: effects of plasma-working gases, degradation pathways and toxicity assessment. Chemosphere. 2018;204:351-8.

26. Liu Y, Zhang H, Sun J, Liu J, Shen X, Zhan J, Zhang A, Ognier S, Cavadias S, Li P. Degradation of aniline in aqueous solution using non-thermal plasma generated in microbubbles. Chem Eng J. 2018;345:679-87.

27. Zhang Q, Zhang H, Zhang Q, Huang Q. Degradation of norfloxacin in aqueous solution by atmospheric-pressure non-thermal plasma: mechanism and degradation pathways. Chemosphere. 2018;210:433-9.

28. Chen S, Xiong P, Zhan W, Xiong L. Degradation of ethylthionocarbamate by pyrite-activated persulfate. Miner Eng. 2018;122:38-43.

29. Zrinyi N, Pham AL. Oxidation of benzoic acid by heat-activated persulfate: effect of temperature on transformation pathway and product distribution. Water Res. 2017;120:43-51. 
30. Fang Z, Chelme-Ayala P, Shi Q, Xu C, Gamal El-Din M. Degradation of naphthenic acid model compounds in aqueous solution by UV activated persulfate: influencing factors, kinetics and reaction mechanisms. Chemosphere. 2018;211:271-7.

31. Ke Z, Huang Q, Zhang H, Yu Z. Reduction and removal of aqueous Cr(VI) by glow discharge plasma at the gas-solution interface. Environ Sci Technol. 2011;45:7841-7.

32. Zhang H, Yang L, Yu Z, Huang Q. Inactivation of Microcystis aeruginosa by DC glow discharge plasma: impacts on cell integrity, pigment contents and microcystins degradation. J Hazard Mater. 2014;268:33-42.

33. Shang K, Wang X, Li J, Wang H, Lu N, Jiang N, Wu Y. Synergetic degradation of Acid Orange 7 (AO7) dye by DBD plasma and persulfate. Chem Eng J. 2017;311:378-4.

34. Chen J, Feng J, Lu S, Shen Z, Du Y, Peng L, Nian P, Yuan S, Zhang A. Non-thermal plasma and Fe ${ }^{2+}$ activated persulfate ignited degradation of aqueous crystal violet: degradation mechanism and artificial neural network modeling. Sep Purif Technol. 2018;191:75-85.

35. Ji Y, Shi Y, Wang L, Lu J, Ferronato C, Chovelon JM. Sulfate radical-based oxidation of antibiotics sulfamethazine, sulfapyridine, sulfadiazine, sulfadimethoxine, and sulfachloropyridazine: formation of $\mathrm{SO}_{2}$ extrusion products and effects of natural organic matter. Sci Total Environ. 2017;593594:704-12.

36. Tang S, Yuan D, Rao Y, Li N, Qi J, Cheng T, Sun Z, Gu J, Huang H. Persulfate activation in gas phase surface discharge plasma for synergetic removal of antibiotic in water. Chem Eng J. 2018;337:446-54.

37. Wang C, Liang C. Oxidative degradation of TMAH solution with UV persulfate activation. Chem Eng J. 2014;254:472-8.

38. Liang $\mathrm{C}, \mathrm{Su} \mathrm{H}$. Identification of sulfate and hydroxyl radicals in thermally activated persulfate. Ind Eng Chem Res. 2009;48:5558-62.

39. Izadifard M, Achari G, Langford CH. Degradation of sulfolane using activated persulfate with UV and UV-ozone. Water Res. 2017;125:325-31.

40. Wu D, Li X, Zhang J, Chen W, Lu P, Tang Y, Li L. Efficient PFOA degradation by persulfate-assisted photocatalytic ozonation. Sep Purif Technol. 2018;207:255-61.

41. $\mathrm{Hu}$ P, Long M. Cobalt-catalyzed sulfate radical-based advanced oxidation: a review on heterogeneous catalysts and applications. Appl Catal B. 2016;181:103-17.

42. Olmez-Hanci T, Arslan-Alaton I. Comparison of sulfate and hydroxyl radical based advanced oxidation of phenol. Chem Eng J. 2013;224:10-16.

43. Guo H, Gao N, Yang Y, Zhang Y. Kinetics and transformation pathways on oxidation of fluoroquinolones with thermally activated persulfate. Chem Eng J. 2016;292:82-91.

44. Wang G, Zhao D, Kou F, Ouyang Q, Chen J, Fang Z. Removal of norfloxacin by surface Fenton system $\left(\mathrm{MnFe}_{2} \mathrm{O}_{4} / \mathrm{H}_{2} \mathrm{O}_{2}\right)$ : kinetics, mechanism and degradation pathway. Chem Eng J. 2018;351:747-55.

45. Cao D, Wang Y, Qiao M, Zhao X. Enhanced photoelectrocatalytic degradation of norfloxacin by an $\mathrm{Ag}_{3} \mathrm{PO}_{4} / \mathrm{BiVO}_{4}$ electrode with low bias. J Catal. 2018;360:24--9.

46. Niu XZ, Busetti F, Langsa M, Croué JP. Roles of singlet oxygen and dissolved organic matter in self-sensitized photo-oxidation of antibiotic norfloxacin under sunlight irradiation. Water Res. 2016;106:214-22.

47. Guo H, Ke T, Gao N, Liu Y, Cheng X. Enhanced degradation of aqueous norfloxacin and enrofloxacin by UV-activated persulfate: kinetics, pathways and deactivation. Chem Eng J. 2017;316:471-80.

48. Li H, Chen J, Hou H, Pan H, Ma X, Yang J, Wang L, Crittenden JC. Sustained molecular oxygen activation by solid iron doped silicon carbide under microwave irradiation: mechanism and application to norfloxacin degradation. Water Res. 2017;126:274-84.

49. Ding D, Liu C, Ji Y, Yang Q, Chen L, Jiang C, Cai T. Mechanism insight of degradation of norfloxacin by magnetite nanoparticles activated persulfate: identification of radicals and degradation pathway. Chem Eng J. 2017;308:330-9.

Volume 8, Issue 4, 2018 
